\title{
Static mechanical allodynia (SMA) is a paradoxical painful hypo-aesthesia: Observations derived from neuropathic pain patients treated with somatosensory rehabilitation
}

\author{
C. J. SPICHER ${ }^{1,2}$, F. MATHIS ${ }^{1}$, B. DEGRANGE ${ }^{1}$, P. FREUND ${ }^{2}$, \& E. M. ROUILLER ${ }^{2}$ \\ ${ }^{1}$ Somatosensory Rehabilitation Centre, Clinique Générale, Fribourg, Switzerland and ${ }^{2}$ Unit of Physiology and Program \\ in Neurosciences, Department of Medicine, Faculty of Sciences, University of Fribourg, Fribourg, Switzerland
}

\begin{abstract}
The present study aimed at investigating the time span it takes to remove a static mechanical allodynia (SMA) in humans suffering from chronic peripheral neuropathic pain. Forty-three subjects were included in the study and, during somatosensory rehabilitation, their SMA territory was precisely mapped. They then underwent distant vibrotactile counter stimulation (DVCS) treatment. It was observed that, with DVCS, SMA disappeared in all cases, and was transformed into an underlying hypoaesthesia. It was found that the "tenderness to touch" symptom (which is SMA) was located in the same territory as the underlying hypoaesthesia, which was located on a part of the cutaneous territory of a partially damaged nerve. These results demonstrate that treating patients suffering from neuropathic pain with DVCS revealed a skin territory of denervation that was previously masked by SMA. Thus, SMA can be considered as a paradoxical painful hypoaesthesia. Furthermore, mapping SMA is a valuable source of information for our understanding of abnormal sensory processing in neuropathic pain patients. We conclude that the mapping of the zone of hypersensitivity on the skin in humans suffering from chronic peripheral neuropathic pain improves diagnosis. The mapping of the zone of hypersensitivity is a tool to presume which branch of the peripheral nerve is damaged. The location of the axonal lesions is at the periphery, while the mechanism of pain sensitization is probably central and referred peripherally to the skin by a painful hypoaesthesia.
\end{abstract}

Keywords: Hypersensitivity, burning sensation, extraterritorial neuropathic pain, axotomy, peripheral neuropathic pain, hypoaesthesia

\section{Introduction}

Mechanical allodynia (MA) was first defined in humans by Merskey (1979) and revised a few years later: MA is a "Pain due to a stimulus which does not normally provoke pain" (Merskey and Bogduk 1994). More specifically, MA is a neuropathic pain provoked by application of a tactile stimulus which normally does not elicit pain on the skin. Based on the recommendations of the IASP (International Association for the Study of Pain), MA is distinct from hyperalgesia, a term reserved for an increase of pain sensitivity to a noxious stimulus. There has been much debate on the topic of peripheral neuropathic pain, in particular on the issue of whether MA is caused by damaged $\mathrm{A} \beta$ fibres. A possible reason for the controversies about the mechanisms underlying MA is that MA is fundamentally paradoxical. Partial denervation of the skin is expected to blunt sensation, not to amplify it in a noxious way (Sukhotinsky et al. 2004; Devor 2006). The term "burning numbness" has been used to describe this paradox (Campa and Payne 1993). A second reason for a debate on MA, namely, considering $\mathrm{MA}$ as an expression of $\mathrm{A} \beta$ fibre lesions, is that the location of the axonal lesions at the periphery is distinct from the site of pain sensitization.

MA is believed to be initiated by a massive, spontaneous ectopic firing originating from the neuroma as well as in axotomized sensory neurons in dorsal root ganglia, occurring a few hours after a lesion of a peripheral nerve (e.g., Sukhotinsky et al.

Correspondence: C. J. Spicher, Somatosensory Rehabilitation Centre, Clinique Générale, Hans-Geiler St. 6, CH-1700 Fribourg, Switzerland. E-mail: reeducation.sensitive@cliniquegenerale.ch 
2004). The ectopic firing then leads to initiation and maintenance of central sensitization (Sukhotinsky et al. 2004; Devor 2006), most likely due to neurochemical changes taking place in the spinal cord (e.g., Ji and Woolf 2001). In line with this interpretation, when the ectopic peripheral input was suppressed, central sensitization decreased and MA was eliminated (Devor 2006). The mechanism of central sensitization, leading to a decrease of pain threshold in the spinal cord, was referred to an increased synaptic efficacy, reminiscent to some extent of the synaptic plasticity underlying longterm potentiation (LTP) in the hippocampus or cerebral cortex (Ji et al. 2003). It is believed that in the presence of central sensitization, inputs along intact low-threshold cutaneous afferents in the territories of neighbouring not-injured nerves provoke pain in response to light tactile stimulation (e.g., Cervero and Laird 1996; Campbell and Meyer 2006) [overlapping pain (Rowbotham and Fields 1989; Rowbotham et al. 1996b; Fields et al. 1998) or extraterritorial pain (Decosterd and Woolf 2000; Malan et al. 2000)]. More specifically, synaptic efficacy is considered to be initially increased in the nociceptors (homotypic potentiation) leading in a second step, to increase of efficacy in synapses formed by low-threshold mechano-sensitive $\mathrm{A} \beta$ fibres (Ji et al. 2003). Whereas pain caused by light touch (allodynia) is related to signals transferred by $\mathrm{A} \beta$ fibres, secondary hyperalgesia in adjacent territories is mediated by $\Delta$ - or C-nociceptors (e.g., Ziegler et al. 1999). This stage of allodynia-like signs in not-injured nerve territories probably reflects the increase of sensitivity in the primary sensory neurons due to an abnormal excitable peripheral state as well as the increase in excitability and extension of receptive fields of dorsal horn neurons related to central sensitization (Decosterd 2006). The phenomenon of central sensitization extended to $\mathrm{A} \beta$ fibres leads to a misunderstanding of the symptom being detected peripherally by stimulating the skin. Another potential generator of neuropathic pain is a possible contribution of the intact nociceptors. Their firing pattern is modified as a result of local exposure at the periphery to damaged fibres subjected to a process of Wallerian degeneration. This second mechanism would thus correspond to a kind of peripheral sensitization (e.g., Campbell 2001; Wu et al. 2001; Campbell and Meyer 2006). Along this line, a recent study reported a long-term change of sympathetic and sensory innervations of the skin after peripheral nerve injury, which may be involved in the development and maintenance of neuropathic pain (Yen et al. 2006). In animal models of neuropathic pain, MA is observed in specific territories that are related to the type of injury, for instance, traumatic, compressive, infectious, systemic, etc. (Bennett and
Xie 1990; Kim and Chung 1992; Decosterd and Woolf 2000; Ossipov et al. 2000; Campbell and Meyer 2006).

The definition of MA includes the amplitude of the stimulus and the intensity of the perceived pain. A third parameter that is also involved in the definition of MA is the territory to which the stimulus is applied and how the stimulus is applied. MA is usually tested by applying a brush stroke on the skin. As the stimulus is moved on the skin surface, this brush-evoked allodynia is in fact a dynamic MA, for which a standardized test is difficult to define (no precise control of the site of application and of the amplitude of tactile stimulation), thus raising questions about its reliability. In the present study, the stimulus used to delineate a territory of MA is a static force of $15 \mathrm{~g}$ applied perpendicularly with an aesthesiometer at a punctuate site on the skin (Spicher 2006). As the stimulus is not displaced in parallel to the skin surface, we introduce here the term of static mechanical allodynia (SMA), reflecting the static stimulus application mode. The application of the same stimulus is then repeated at different punctuate sites on the skin, to precisely delineate the SMA territory, a procedure referred to as "allodynography" (as shown in Figure 1).

In humans, the territory on the skin eliciting this pain symptom of burning sensation (or SMA) can be precisely mapped by establishing its "allodynography", as shown in Figure 1A for a patient exhibiting a well-defined SMA territory on the lateral side of the right foot (violet area). We report here data derived from 43 patients suffering from nerveinjury-induced SMA, altogether exhibiting 63 SMA territories determined by allodynography. During several weeks, the patients were then subjected to somatosensory rehabilitation, consisting of gentle, distant vibrotactile counter stimulation (DVCS) treatment. The vibratory tactile stimulus $(100 \mathrm{~Hz})$ is applied first at some distance from the SMA territory but, session after session, it progressively and slowly invades the SMA territory forming new zones where the stimulus is not perceived as painful anymore but comfortable. Using this approach, the aim of the present paper is to test the hypothesis that the initial SMA territory is transformed into a hypoaesthetic territory as a result of DVCS treatment. In other words, the effect of the DVCS therapy is to provoke a progressive shrinkage of the SMA territory, revealing the presence of an underlying mechanical hypoaesthesia.

\section{Materials and methods}

Forty-three patients were included in the study, based on the following inclusion criteria (Table I): first, presence of neuropathic pain and 
A

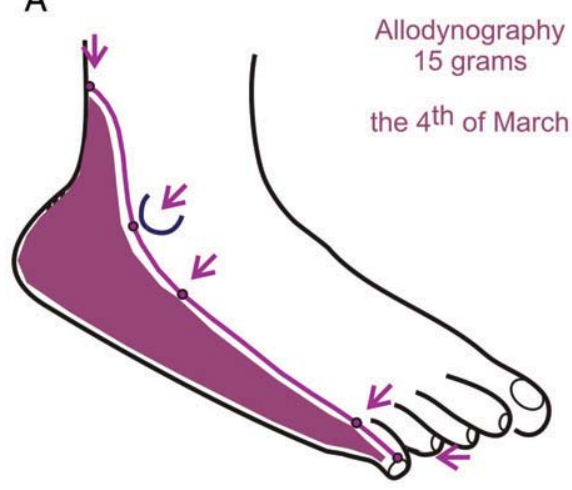

C

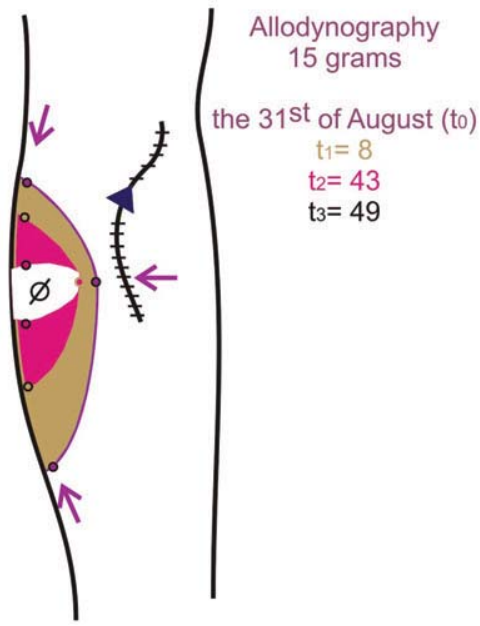

B

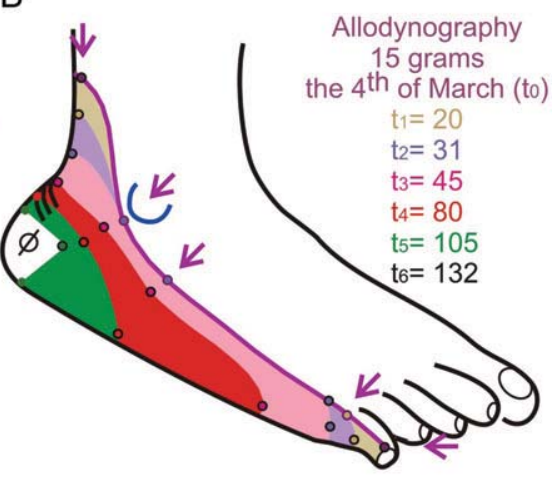

D

15 grams

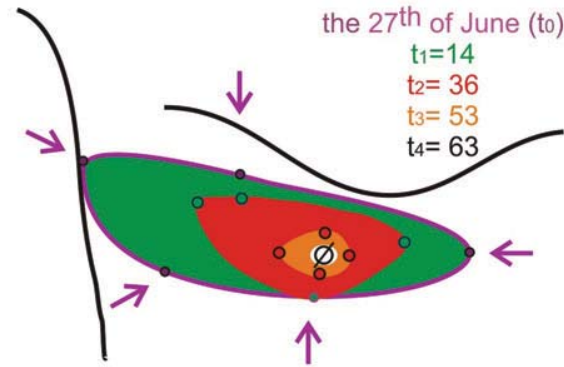

Figure 1. (A) Example of allodynography in a typical patient, delineating the violet territory on the foot (lateral calcaneal nerve) where the application of a force of $15 \mathrm{~g}$ provoked a touch-evoked pain (SMA) of $3 / 10 \mathrm{~cm}$ on the visual analogue scale (VAS) of pain (see Appendix A). (B) Time course of the progressive shrinkage of the SMA territory, as a result of treatment from 4 March $\left(t_{0}\right)$ until 14 July $2005\left(t_{6}\right) ; t_{1}$ is the time interval in days separating the day of testing from $t_{0}$ etc. The date at which a complete disappearance of the SMA territory was observed is 14 July 2005, replaced by the underlying hypoaesthesia of the lateral calcaneal nerve. (C) Time course of the progressive shrinkage of the SMA territory for the anterior branch of medial cutaneous nerve of the forearm. Same conventions as in B. (d) The time course of the progressive shrinkage of the SMA territory for the lateral cutaneous branch of the 6th intercostal nerve. Same conventions as in B.

Table I. Origin of the 43 patients with peripheral neuropathic pain syndromes and their 63 static mechanical allodynia (SMA) territories included in the study out of a larger population of 241 neuropathic pain patients under somatosensory rehabilitation.

159 patients with initial hypoaesthesia

22 patients interrupted their DVCS treatment

17 patients still under treatment at onset of the analysis

241 neuropathic

pain patients

$\begin{array}{cc}82 \text { patients } & 60 \text { patients } \\ \text { with SMA } & \text { treated with DVCS }\end{array}$

43 patients for whom the 63 SMA

territories have already disappeared

at onset of the analysis

The 241 neuropathic pain patients were treated in the Somatosensory Rehabilitation Centre (Fribourg), from 1 July 2004 until 23 November 2005. One hundred and fifty-nine neuropathic pain patients presented a hypoaesthesia. Eighty-two neuropathic pain patients presented a SMA. Twenty-two patients interrupted their distant vibrotactile counter stimulation (DVCS) treatment. By 23 November 2005 , 17 patients still remained with an incomplete disappearance of SMA (treatment ongoing).

SMA on the day of initial testing; second, as a result of the somatosensory rehabilitation, the SMA territory disappeared at the time of analysis. Overall, amongst the 241 neuropathic pain patients treated in the Somatosensory Rehabilitation Centre (Fribourg, Switzerland), from July 2004 until November 2005, 159 patients presented a hypoaesthesia and 82 presented a SMA. Patients with persisting SMA in 
November $2005(n=17)$ or who interrupted their somatosensory rehabilitation before its disappearance $(n=22)$ were discarded as they did not fulfil the inclusion criteria. These interruptions of treatment were due either to the incidence of another medical disorder (e.g., stroke) or the free choice by the patient to follow another treatment (e.g., acupuncture). Finally, 43 patients were included in the study (Table I). No patient presenting neuropathic pain and SMA at the beginning of the somatosensory rehabilitation followed by disappearance of SMA after treatment (inclusion criteria) was excluded. From the day of the initial testing, the mean duration of the neuropathic chronic pain (defined as a pain lasting 6 months or more) presented by the 43 patients suffering from SMA was 35 months $\pm S D=21$ months (range: 7-523 months). Patients were usually sent to the Somatosensory Rehabilitation Centre by a prescribing medical doctor in order to be tested and rehabilitated according to the somatosensory rehabilitation method described below (see also Dellon 2000; Spicher 2006).

\section{Procedure}

Three therapists treated the 43 patients for their SMA and performed the tests described below. Each patient was individually assessed by at least two of the three therapists. The somatosensory rehabilitation was organized on the basis of one weekly session, with another therapist every other week (two therapists in total, but not three). The tests were performed during the treatment sessions in the same room in which the temperature was maintained at $20 \pm 1^{\circ} \mathrm{C}$. As a result of the therapy, the SMA territory progressively shrank, and along the consecutive sessions, the time course of progressive SMA territory shrinkage until disappearance was assessed using either allodynography or the rainbow pain scale procedure (see below), but never using both simultaneously (see Discussion).

\section{Somatosensory testing}

Two tests were used to quantify the progressive impact of SMA treatment, as previously reported (Spicher 2006):

- The allodynography, quantifying the location and extent of the SMA territory (Appendix A and Figure 1A).

- The rainbow pain scale, quantifying the severity of the SMA (Appendix B and Figure 2).

Allodynography (see Appendix A for a detailed description of the procedure). The allodynography (Spicher 2006) is a technique to quantify and map a SMA territory on the skin, a test inspired by a definition of allodynia: "Gentle mechanical stimuli (e.g. bending of hairs) may evoke severe pain" (Fields 1994). The test is conducted by varying the application site of the stimulus in order to delineate the borders of the SMA territory. This test allows visual inspection

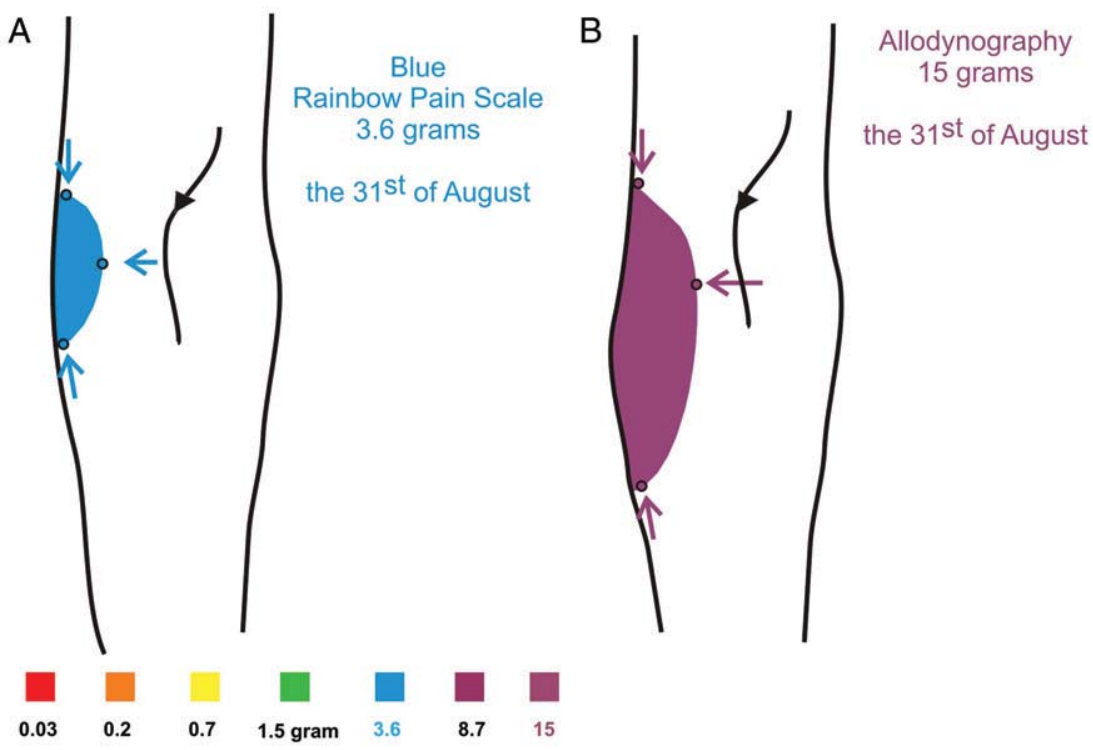

Figure 2. A territory corresponding to the blue colour on the rainbow pain scale (panel A; see Appendix B) is smaller at the same date than its allodynography (panel B). The touch-evoked pain (SMA) is the same (VAS $=3 / 10 \mathrm{~cm}$ ), but the application force was different: panel A, $3.6 \mathrm{~g}$; panel B, $15 \mathrm{~g}$. The skin territory corresponds a posteriori to the innervation zone of an anterior branch of the medial cutaneous nerve of forearm. 
(both by the therapist and the patient) of the progressive SMA territory shrinkage during treatment. Figures 1B-D show how allodynographywhen conducted at time intervals of usually 2-4 weeks-monitors the progressive shrinkage of the SMA territory.

Rainbow pain scale (Appendix B). The rainbow pain scale (Spicher 2006) is a procedure aimed at establishing the severity of the SMA. Symbolically, this test passes through the seven colours of the rainbow (Figure 2), going from red to violet, each colour corresponding to increasing force levels $(0.03-15 \mathrm{~g})$, applied using aesthesiometers (Figure 3A). In order to map the SMA territory, the contour of the painful skin territory is determined using a $15 \mathrm{~g}$ aesthesiometer (corresponding to violet in the rainbow pain scale). As the pain tolerance threshold of the patient was strictly respected during this procedure, the SMA territory itself was not touched with the $15 \mathrm{~g}$ aesthesiometer. Nevertheless, it was possible to investigate the severity of the SMA by testing the painful territory with lighter pressure forces tolerated by the patient. The rainbow pain scale is then an estimate of the pain intensity within the SMA territory, obtained by application of the slightest aesthesiometer (going from red to violet) provoking pain. The pain invariant is defined as $3 \mathrm{~cm}$ from the left on a visual analogue scale (VAS) of a total length of $10 \mathrm{~cm}$, in the absence of spontaneous neuropathic pain at rest (red line in Figure 3B, top). In contrast, if the patient has spontaneous neuropathic pain at rest, the pain invariant is defined as the pain at rest $+1 \mathrm{~cm}$. For instance, if the pain at rest assessed by the patient the day of testing is 4 , then the pain invariant is 5 (Figure 3B, bottom). Figure 2 illustrates that, as expected, the blue rainbow pain scale $(3.6 \mathrm{~g})$ is smaller than the SMA territory derived from allodynography $(15 \mathrm{~g})$.

Once the SMA progressively disappeared as a result of the DVCS treatment, two tests were used to demonstrate the presence of an underlying hypoaesthesia:

- The secondary aesthesiography, providing an estimate of the location and extent of the underlying hypoaesthesia (Appendix $\mathrm{C}$ and Figure 4B).

- The pressure perception threshold (PPT), quantifying the amplitude of the underlying hypoaesthesia.

Secondary aesthesiography (Appendix $C$ ). The secondary aesthesiography is conducted after complete shrinkage of the SMA territory, with the aim to quantify the underlying hypoaesthesia. The term "aesthesiography" is used because it refers to a mapping of the hypoaesthesia, while "secondary" is used to avoid any misunderstanding with proper aesthesiography (Létiévant 1876; Trotter and Davies 1907; Tinel 1917; Inbal et al. 1987; Spicher and Kohut 2001). Aesthesiography is a very sensitive test, which is part of the diagnosis of axonal lesions (Spicher et al. 2005; Spicher 2006). By definition, the SMA is considered as "disappeared" when the application of an aesthesiometer of $15 \mathrm{~g}$ does no longer elicit pain, representing the onset of secondary aesthesiography. Figure 4 illustrates the transition from SMA to underlying hypoaesthesia.

Short-form pressure perception threshold. The PPT, introduced by von Frey (1896), is a test used to determine the patient's ability to perceive the application of a force on the skin. It is conducted

A

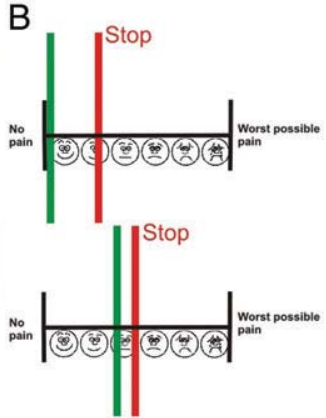

Figure 3. (A) Aesthesiometer kit used to conduct the rainbow pain scale test (see Appendix B). (B) The pain invariant is defined by the therapist with a red line at $3 \mathrm{~cm}$ from the left (top) on a visual analogue scale (VAS) of a total length of $10 \mathrm{~cm}$, in the absence of spontaneous neuropathic pain at rest (green line). In contrast, if the patient has spontaneous neuropathic pain at rest defined by himself with a green line (bottom), the pain invariant is defined as the pain at rest $+1 \mathrm{~cm}$ (red line drawn by the therapist). If the pain at rest assessed by the patient the day of testing is 4 , then the pain invariant is 5 . 

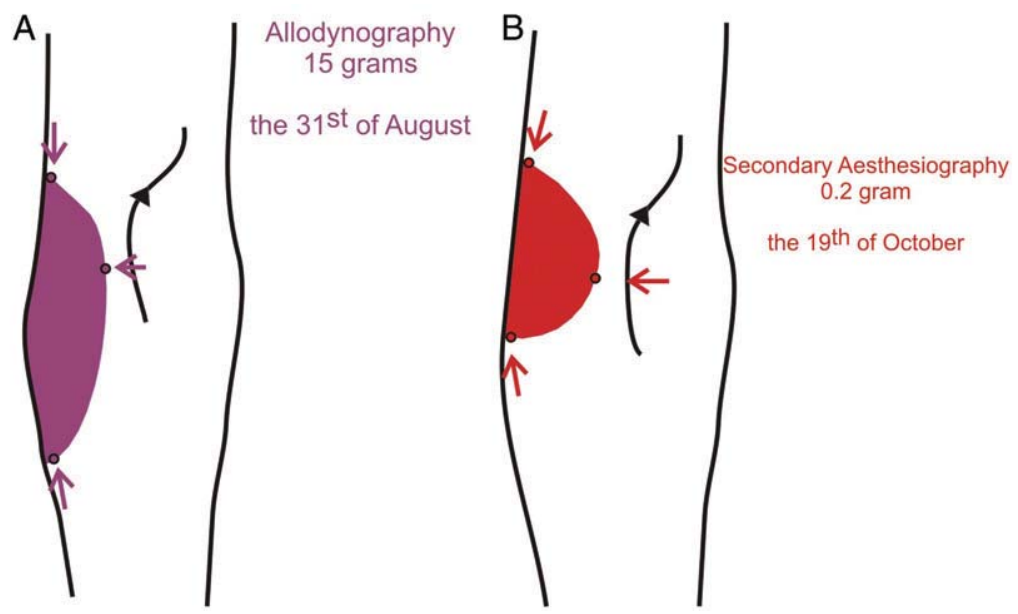

Figure 4. When the SMA territory determined by allodynography disappeared (panel A), the presence of an underlying hypoaesthetic territory was found, based on a secondary aesthesiography procedure (panel B; see Appendix C). (A) Allodynography (31 August 2005, the application of a force of $15 \mathrm{~g}$ provoked a touch-evoked pain (SMA) of $3 / 10 \mathrm{~cm}$ on the VAS). (B) Secondary aesthesiography (19 October 2005, the application of a force of $0.2 \mathrm{~g}$ was not detected).

during the session following the disappearance of the SMA. If applied earlier, when the SMA is still present, the application of the stimulus may trigger a reappearance of the SMA. We have chosen the test application proposed by Semmes et al. (1960) and modified later by Malenfant et al. (1998), to reduce the duration of the test and also to diminish the risk of SMA reappearance. The PPT is based on the application of seven aesthesiometers (from the kit of 20) (for more details, see Spicher 2006). The shortform PPT score is given by the mean value of the force application of the three aesthesiometers detected in an ascending, descending, and ascending series (ADA) (Spicher et al. 2006). ${ }^{1}$ In the ascending series (from the thinnest to the thickest of the seven aesthesiometers), it is the first one detected by the patient. In the descending series (from the thickest to the thinnest), it is the last one detected.

\section{Somatosensory rehabilitation}

The somatosensory rehabilitation offered to the 43 patients was based on a method developed in the Somatosensory Rehabilitation Centre and described earlier in detail (Spicher 2006). This method can be taught to a therapist in $35 \mathrm{~h}$. Briefly, the duration of each weekly session of somatosensory rehabilitation ranges between 30 and $75 \mathrm{~min}$ (average time: $45 \mathrm{~min}$ ). The somatosensory rehabilitation comprises three treatment phases: (1) Distant vibrotactile counter stimulation (DVCS), in the presence of a possible allodynic territory (which was the case initially for the 43 patients in the present study).

(2) Rehabilitation of hyposensitivity.

Desensitization by mechanical vibrations at the site of axonal lesions. The DVCS treatment begins in the presence of a SMA territory (Table II) and is pursued until its complete disappearance, at which time the rehabilitation of hyposensitivity on the hypoaesthetic territory can be initiated. The aims of the rehabilitation of hyposensitivity are to diminish the hypoaesthesia and to attenuate simultaneously the spontaneous neuropathic pain. In the present study, the somatosensory rehabilitation is described only for its first phase, the DVCS treatment, aimed at eliminating the SMA territory.

Distant vibrotactile counter stimulation (DVCS). Distant vibrotactile counter stimulation (Spicher 2006) is a neologism. This new technique uses a tactile and vibratory device, allowing the patient to perceive a non-nociceptive stimulus in a non-nociceptive manner on a cutaneous territory that is initially allodynic. The variable parameter of the DVCS is the localization of the stimulus application, but not its amplitude. At this point, the task of the somatosensory therapist is:

(i) First, to presume which branch of the cutaneous nerve affected is damaged. It is not possible to determine it at this stage, as the extraterritorial pain is overlapping the cutaneous distribution of the damaged nerve.

(ii) To define a limited zone of the skin where DVCS should be applied once a week in the presence of the therapist at the rehabilitation centre and to train the patient to perform his own therapy by application of tactile stimuli, 6 times a day for $1 \mathrm{~min}$ at home.

(iii) To delineate a limited zone of the skin to be avoided as much as possible. 
Table II. In presence of SMA, the rehabilitation of the hyposensibility is preceded by the DVCS to treat the touch-evoked pain.

\begin{tabular}{lcc}
\hline & Touch-evoked pain & Spontaneous pain \\
\hline $\begin{array}{l}\text { Static mechanical } \\
\text { allodynia (SMA) }\end{array}$ & Yes & $\begin{array}{c}\text { Rehabilitation of the } \\
\text { underlying hyposensibility }\end{array}$ \\
& $\downarrow$ & \\
\hline $\begin{array}{l}\text { Hypoaesthesia } \\
\text { (not included in this study) }\end{array}$ & No & $\begin{array}{c}\text { Rehabilitation of the } \\
\text { hyposensibility }\end{array}$ \\
\hline
\end{tabular}

A

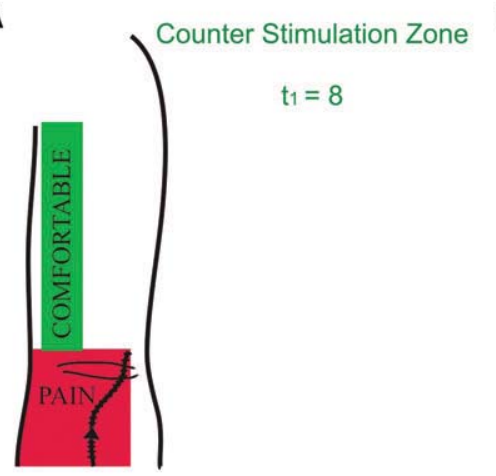

C

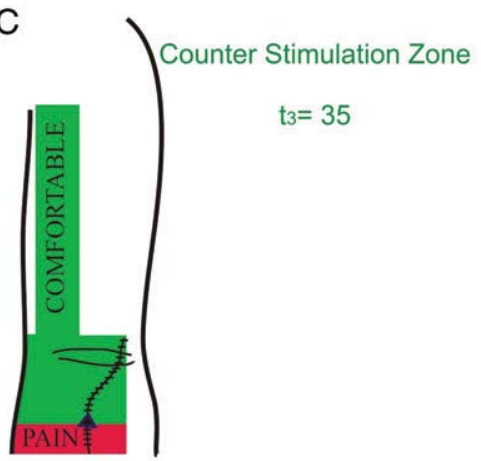

B

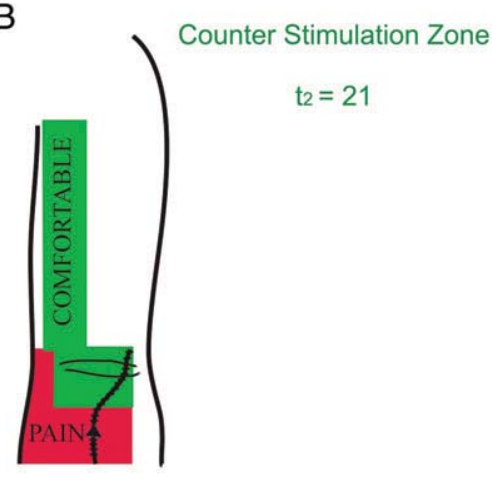

D

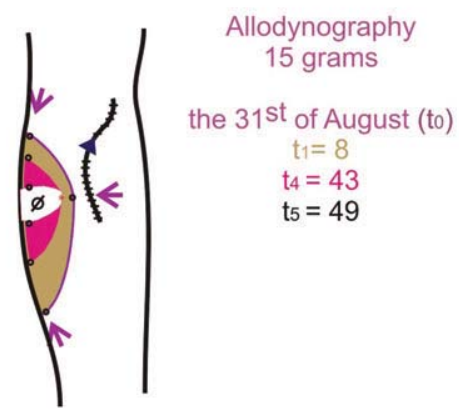

Figure 5. Schematic diagram showing the progressive change of the skin zone on the forearm (in green) where to apply the "distant vibrotactile counter stimulation (DVCS)", together with the skin area to avoid (in red). (A-C) The counter stimulated zone progressively invaded the zone that was to be avoided (i.e., the presumed anterior branch of medial cutaneous nerve of the forearm damaged). The time intervals between the sessions in panels A, B, and C is given in days. (d) During the same period, the SMA territory progressively disappeared (for more details see also the legend of Figure 1C). The day when the SMA disappeared $\left(t_{3}=50\right.$ days after onset of DVCS treatment), the underlying hypoaesthesia appeared and the DVCS treatment was interrupted. A posteriori, as the skin territory of the underlying hypoaesthetic territory corresponds to the innervation of an anterior branch of medial cutaneous nerve of forearm, we concluded that the aetiology of the SMA was a lesion of the anterior branch of medial cutaneous nerve of the forearm.

The cutaneous zone to counter stimulate, perceived as comfortable, and the zone to avoid, perceived as less comfortable, are tested and defined at each session. The results are presented to the patient on a map. During the course of treatment, it will become possible for the patient to progressively invade the "old" allodynic territory with the same comfortable stimulus. Figure 5 illustrates how the zones of application of DVCS invade the SMA territory, which progressively disappears. The SMA is treated by distant tactile counter stimulation (i.e., rabbit skin) at home and by DVCS during the weekly therapeutic session at the rehabilitation centre (parameters of stimulation: frequency $100 \mathrm{~Hz}$; amplitude $0.06 \mathrm{~mm}$ ) (Spicher et al. 2005). In sharp contrast to previous reports (Rowbotham et al. 1996a; Galer et al. 1999), the counter stimulus is not applied on the painful skin. 


\section{Results}

Subjects: Neuropathic pain syndromes

Table III shows the neuropathic pain syndromes presented by the 43 patients on the day of initial testing. Table IV shows the severity of peripheral chronic neuropathic pain symptoms, as established for the 43 patients at initial testing. The less severe mechanical allodynia was found in patients exhibiting a SMA characterized by an absence of pain at rest (Stage II). The neuralgic prodrome (Stage III) is distinguished from the neuralgic syndrome (Stage IV): the former has intermittent pain whereas the latter has persistent pain (Spicher 2006). Finally, Complex Regional Pain Syndrome of type II (Bruehl et al. 1999) corresponds to a peripheral neuropathic pain syndrome (Stage V) (Mackinnon 1988; Gracely et al. 1992; Albrecht et al. 2006; Oaklander et al. 2006), characterized by the boiling sensation ("as if eggs were being boiled in the limb"; Mitchell 1872). In the present study, each patient presented a SMA, but neuropathic syndromes may, of course, also occur with an initial hypoaesthesia.

\section{Branch of cutaneous nerve damaged}

Forty-three patients were included in the study. As we hypothesize that the initial SMA territory is

Table III. Summary of peripheral neuropathic pain syndromes observed on initial examination of the patients $(n=43)$.

\begin{tabular}{lc}
\hline Diagnosis & $\begin{array}{c}\text { Number } \\
\text { of patients }\end{array}$ \\
\hline Trigeminal neuralgia & 2 \\
Occipital neuralgia & 1 \\
Cervical neuralgia & 2 \\
Brachial neuralgia & 8 \\
Intercostal neuralgia & 8 \\
Lumbo-abdominal neuralgia & 2 \\
Femoral neuralgia & 8 \\
Meralgia paraesthetica & 1 \\
Sciatic neuralgia & 11 \\
Total & 43 \\
\hline
\end{tabular}

transformed into a hypoaesthetic territory, the somatosensory therapist must presume the branch of the nerve damaged in order to define the DVCS treatment guidelines. Due to the phenomenon of extraterritorial pain, at that step, the somatosensory therapist can thus only presume the branch of the nerve affected by the lesion. Thus the identification of the branch of the nerve damaged can be done only a posteriori, when the underlying hypoaesthesia appears. Table $\mathrm{V}$ lists the cutaneous nerves that were damaged in the group of the 43 patients presenting overall 63 SMA territories. Some of the patients had more than one (two or three) SMA territory, such as a brachial neuralgia and an intercostal neuralgia.

\section{Painful hypoaesthesia disappearance}

After DVCS treatment, the 63 SMA territories disappeared (inclusion criterion). We observed that $100 \%$ of them switched into a hypoaesthetic territory, referred to as underlying hypoaesthesia. None of the SMA territory became immediately normosensitive at the end of the DVCS treatment (Table VI).

\section{Time course of SMA disappearance as a result of DVCS treatment}

On average, a period of 70 days, thus 10 sessions, $\pm \mathrm{SD}=66$ days (range: 8-206 days) of treatment (DVCS) was necessary to eliminate the SMA. To address the issue of whether the duration of DVCS treatment is related to the severity of the SMA, the progressive disappearance of each colour in the rainbow pain scale into the next colour was investigated. For example, in the case of SMA territory 47, the green aesthesiometer $(1.5 \mathrm{~g})$ did not evoke pain, but the next aesthesiometer did (the "blue" aesthesiomether- $3.6 \mathrm{~g}$ ), on the date of the initial somatosensory testing. When the blue aesthesiometer did not provoke pain anymore, the rainbow pain scale switched into indigo $(8.7 \mathrm{~g})$, eliciting the invariant pain (i.e., $3 \mathrm{~cm} / 10 \mathrm{~cm}$ on the VAS).

Table IV. Severity of peripheral neuropathic pain symptoms ( $n=43$ patients).

\begin{tabular}{llllr}
\hline Stage & \multicolumn{1}{c}{ Diagnosis } & \multicolumn{1}{c}{ Neuropathic pain } & System & Number \\
\hline Stage II & Simple mechanical allodynia & Pressure-evoked pain without spontaneous pain & Somatosensory \\
Stage III & Neuralgic prodrome $^{\mathrm{a}}$ & Pressure-evoked pain and intermittent pain & Somatosensory & 15 \\
Stage IV & Neuralgic syndrome $^{\mathrm{a}}$ & Pressure-evoked pain and persistent pain & Somatosensory & 16 \\
Stage V & CRPS II $^{\mathrm{a}}$ & Pressure-evoked pain and sensation of boiling & Sympathetic & 7 \\
& & & Somatomotor \\
& & & Somatosensory
\end{tabular}

\footnotetext{
${ }^{a}$ With initial SMA in this study, but these syndromes may also present a hypoaesthesia (see Table I: 159 patients with initial hypoaesthesia).
}

Note: Patients with basic cutaneous disorders and no neuropathic pain (Stage I) were not included. 
Figure 6 illustrates the distribution of the colour transitions in the rainbow pain scale and their stages of disappearance colour by colour for the 63 SMA territories analysed in the present study. Moreover, Figure 6 shows the distribution of the initial touchevoked pain severity for all SMA territories included in the study. On average, 24 days of treatment were necessary to transform step by step the 158 rainbow pain scale colours into the next colour. The time course of disappearance from one rainbow pain scale value into the next one is not linear (Figure 7). It takes longer to overcome a green rainbow pain scale ( $1.5 \mathrm{~g}$ provoking pain) than to overcome a blue rainbow pain scale (3.6 g). It takes 49.9 days $\pm S D=32.9$ days to overcome a green rainbow pain scale whereas it takes 33.7 days $\pm S D=20.8$ days to overcome a blue rainbow pain scale.

\section{Quality of the underlying hypoaesthesia}

In the session following the disappearance of SMA, the quality of the underlying hypoaesthesia was measured by the short-form PPT. The average
PPT was $7.8 \mathrm{~g} \pm \mathrm{SD}=14.9 \mathrm{~g}$ (range: $0.3-75 \mathrm{~g}$ ), independently of the cutaneous distribution of the corresponding nerve damage. This result shows the presence of a clear hypoaesthesia, as normal values for PPT are below $1 \mathrm{~g}$, irrespective of the body location.

\section{Discussion}

In the present study, $100 \%$ of the SMA territories $(n=63)$ investigated and treated on the skin of 43 patients completely disappeared, replaced by an underlying hypoaesthetic territory, which was then treated at a later stage. This clinically highly significant result was obtained using the DVCS treatment: weekly in therapy and daily at home by application of tactile stimuli 6 times a day for $1 \mathrm{~min}$. To our knowledge, this is the first report on such a phenomenon in the field of chronic neuropathic pain syndromes in humans. Although the present treatment has been introduced first to handle neuropathic pain at the level of the forearm, more specifically the hand, our data demonstrate that this therapeutic

Table V. Distribution of axonal lesions by the cutaneous department (Valleix's Neuralgia Classification), as presumed during the DVCS treatment and diagnosed a posteriori when the secondary aesthesiography has been undertaken ( $n=43$ patients).

\begin{tabular}{|c|c|c|}
\hline Cutaneous department & $\begin{array}{l}\text { SMA Number } \\
\text { of axonal lesions }\end{array}$ & $\begin{array}{l}\text { Example of axonal lesions } \\
\text { diagnosed a posteriori }\end{array}$ \\
\hline Trigeminal & 2 & Maxillary nerve \\
\hline Occipital & 1 & Greater occipital nerve \\
\hline Cervical & 4 & $\begin{array}{l}\text { Posterior branch of the } \\
7 \text { th cervical nerve }\end{array}$ \\
\hline Brachial & 18 & Posterior brachial cutaneous nerve \\
\hline Thoraco-intercostal & 10 & $\begin{array}{l}\text { Lateral cutaneous branch of the } \\
5 \text { th intercostal nerve }\end{array}$ \\
\hline Lumbo-abdominal & 2 & Ilioinguinal nerve \\
\hline Femoral & 11 & Infrapatellar branch of saphenous nerve \\
\hline Femoro-cutaneous & 1 & Lateral femoral cutaneous nerve \\
\hline Sciatic & 12 & Lateral calcaneal branches of sural nerve \\
\hline Sacral & 2 & Posterior femoral cutaneous nerve \\
\hline Total & 63 & \\
\hline
\end{tabular}

Table VI. The $100 \%$ of SMA territories $(n=63)$, in 43 patients investigated and treated with DVCS, disappeared and then the presence of an underlying hypoaesthesia was revealed in each case.

$\begin{aligned} & \text { Aesthesiography } \\ & \text { contra-productive }{ }^{\mathrm{a}} \text { a priori }\end{aligned}$
$\begin{aligned} & \text { Allodynography } \\ & \text { Absence of observable }\end{aligned}$
tissue damage


approach can be generalized to the entire body surface (Tables III and V). The aim of the present paper was to report on the switch from a SMA territory into a hypoaesthetic territory as a result of the somatosensory rehabilitation. The specific clinical aspects of these basic properties will be described and discussed in more detail elsewhere. The key finding of the present work is the progressive shrinkage of the SMA territory until complete disappearance. These regions demonstrating static mechanical allodynia are also the same regions where an underlying hypoaesthetic territory can be observed once the allodynia has disappeared. This observation provides evidence that the SMA was indeed provoked by a histological loss of large $\mathrm{A} \beta$ afferent fibres. This information clearly indicates that nerve damage is often the source of neuropathic pain, and that the allodynia is most often referred to the zone of greatest denervation: one can conclude that static mechanical allodynia is indeed a paradoxical painful hypoaesthesia. We presume that the underlying mechanical hypoaesthetic territory, revealed here after removal of the SMA territory, was already present from the beginning (immediately after the peripheral nerve lesion), but was already masked at that time by the painful SMA territory. The proposed therapy was thus a two-stage approach: first, remove the SMA territory by gentle tactile stimulation applied at the periphery of the painful zone and then to recover from the hypoaesthesia. The gentle vibrotactile counter-stimulation is applied at the periphery of the SMA territory, which is perceived as comfortable for the patient (Figure 5). The territory on which the DVCS is applied has to

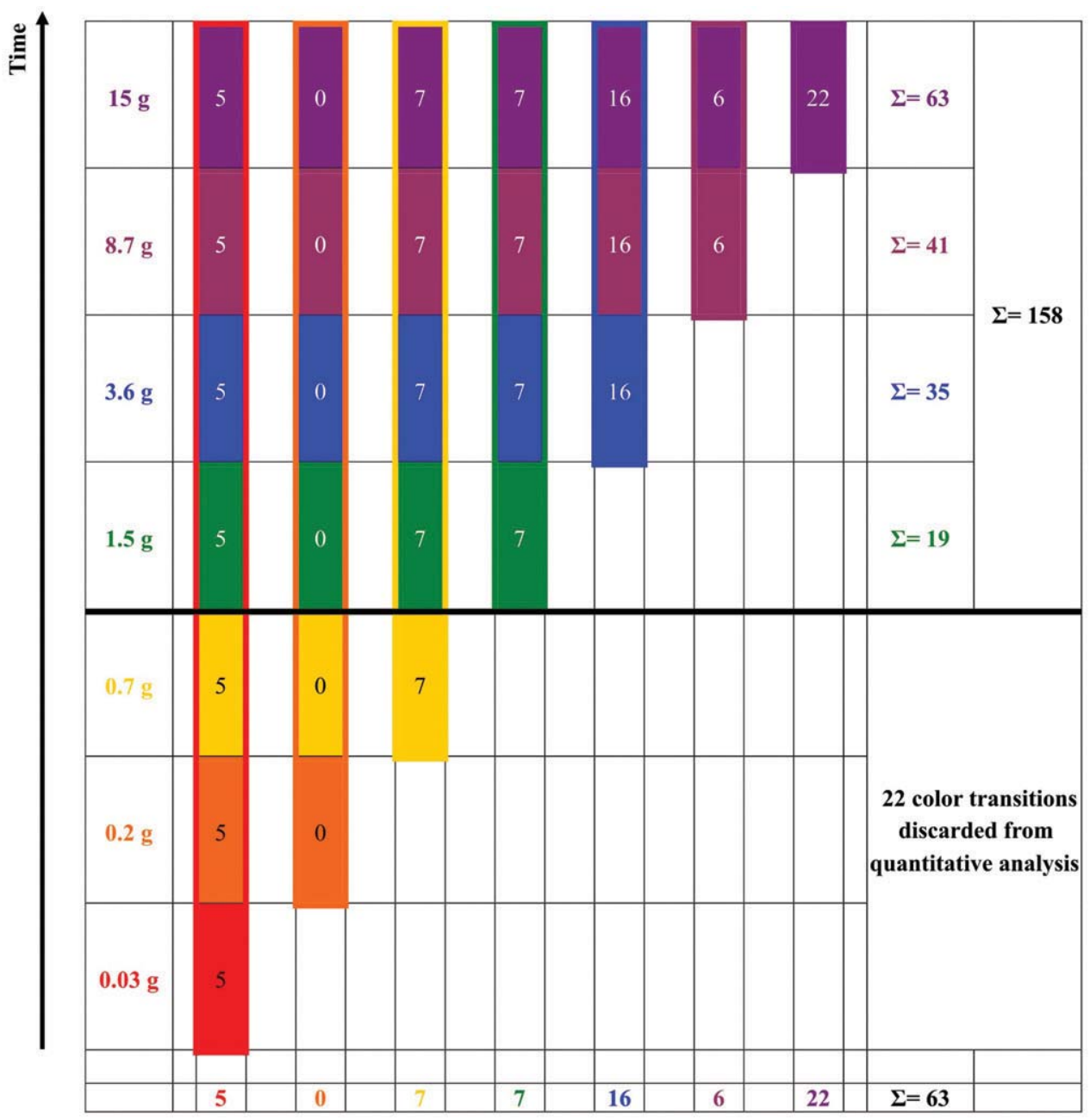

Figure 6. Distribution of the 63 SMA territories as a function of their corresponding rainbow pain scale at the date of the first somatosensory testing (bottom rectangle of each column; the sum of the numbers in the bottom area of all column is 63). Time goes from bottom to top. For further analysis, the 22 colour transitions in the rainbow pain scale below the thick horizontal line have been discarded due to insufficient numbers ( 5 from red to orange, 5 from orange to yellow, and 12 from yellow to green). The upper part of the figure shows the distribution of the 158 colour transitions in the rainbow pain scale during the somatosensory rehabilitation. The time course of disappearance of the 158 steps of the rainbow pain scales is presented in Figure 7. 


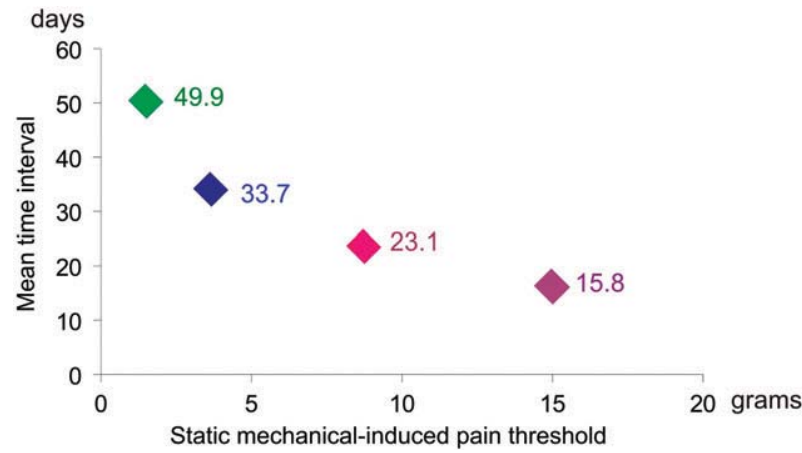

Figure 7. Time course of disappearance of painful hypoaesthesia as a function of the rainbow pain scale. Going from left to right, time values are mean intervals in days to switch from one colour of the rainbow pain scale to the next: switch from 1.5 to $3.6 \mathrm{~g}(n=19)$; from 3.6 to $8.7 \mathrm{~g}$ $(n=35)$; from 8.7 to $15 \mathrm{~g}(n=41)$; from $15 \mathrm{~g}$ (allodynography) to underlying hypoaesthesia (secondary aesthesiography) $(n=63)$

belong to the same spinal dermatome, because no effect is obtained with extra segmental vibrotactile stimulation. Interestingly, when the treatment was interrupted after the first phase, namely, removal of the SMA territory, without proceeding to the recovery from the hypoaesthesia, then the SMA reappears after a few weeks. In other words, the shrinkage and disappearance of the SMA territory is in itself not sufficient to eliminate the stimulusevoked neuropathic pain over the long term; the second stage of treating the hypoaesthesia being necessary in order to permanently eliminate the stimulus-evoked neuropathic pain and the spontaneous neuropathic pain.

As a result of the therapy, the SMA territory progressively shrank. The time course of progressive SMA territory shrinkage was assessed using either allodynography or the rainbow pain scale procedure, but never using both simultaneously (Noël et al. 2005). ${ }^{2}$ When both were tested during the same session, the patient had too much pain for a couple of hours, or even days. Moreover, when both were tested during the same session, instead of observing a progressive SMA territory shrinkage, the rainbow pain scale increased at the next session. For the same reasons the underlying hypoaesthesia is assessed using the secondary aesthesiography and then the PPT procedure, but never using both simultaneously. The PPT is therefore conducted during the session following the disappearance of the SMA and not during the session in order to avoid a reappearance of SMA. Additionally, the PPT procedure was adapted to test an underlying hypoaesthesia into a short-form PPT: the application of the three aesthesiometers is detected in three series (ADA) instead of six series (ADADAD).
A robust recovery from SMA thus requires the two stages of treatment. However, the time point at which the treatment is initiated does not play a major role. Indeed, in the present sample of 43 patients, some suffered from neuropathic pain over a period of several years (up to 45 years). This observation indicates that, even if the central sensitization has been established for a long time, it can still be reversed, at least enough to eliminate the evoked and spontaneous pains. The mechanisms underlying the reversal of central sensitization, in particular how vibrotactile stimuli may relieve pain, are largely unknown (Inui et al. 2006). The "gate control" theory has provided a possible mechanism contributing to this phenomenon (Melzack and Wall 1965), with the hypothesis that influences of large myelinated inputs inhibit the central transmission of signals conveyed by nociceptors, occurring in the dorsal horn of the spinal cord. Based on the precise timing of activities generated in these two separate systems of afferent fibres, a recent work suggested that such inhibition is more likely to occur at cortical than spinal level (Inui et al. 2006). In line with this observation, another study using psychophysical and physiological measures in humans concluded that the inhibition by large diameter fibres takes place at supraspinal level (Nahra and Plaghki 2003). The evoked chronic pain in SMA is elicited by application of a non-noxious tactile stimulus within the SMA territory. To be accepted by the patient, the present therapeutic strategy consists of gentle vibrotactile stimulation of immediately adjacent zones, on which the stimulus is perceived as comfortable. The stimulus applied on the SMA territory activates centrally (in the spinal cord) a network previously subjected to the sensitization (leading to the painful sensation), whereas the tactile stimulus applied on a comfortable neighbouring skin area elicits activity in a second network of neurons. One may then speculate that the second network activated may exert a progressively increasing down regulation of the first network underlying the SMA. As a consequence, the previously sensitized synapses of the first network may undergo plastic changes towards a decrease of efficacy, in analogy with the well-known mechanism of "long-term depression" (LTD), reported for the cerebellum for instance. As the processes of initiation and maintenance of allodynia have been compared to LTP (Ji et al. 2003), it is tempting to hypothesize that the therapeutic removal of the SMA territory is, at least in part, based on mechanisms close to LTD. The rehabilitation of hyposensitivity is most likely based on the neuroplasticity of the somatosensory system (Woolf and Salter 2006). This hypothesis needs to be tested experimentally in animal models of allodynia. 
As outlined in the Introduction, mechanical allodynia emphasizes its central sensitization, in particular in the dorsal root ganglion or in the dorsal horn (e.g., Woolf 1983; Hendry et al. 1999; Mannion et al. 1999; Sindrup et al. 1999; Ji and Woolf 2001; Ji et al. 2003; Sukhotinsky et al. 2004; Devor 2006). The statement "The static mechanical allodynia is a paradoxical painful hypoaesthesia" does not contest the most likely central component of post-injury pain hypersensitivity (Woolf 1983). Few authors remind us that the aetiology of SMA is a damaged nerve (e.g., Woolf and Mannion 1999; Woolf and Salter 2000; Sukhotinsky et al. 2004). Bennett (1994) presumed that "Although [...] the absence of suitable testing, it is possible that neuropathic allodynia is exclusively a disorder of cutaneous sensibility." Devor (1994) described the hypersensitivity as restricted mechano-sensitive tender spots. Rowbotham and Fields (1996) described the apparent paradox that the sensory damaged pathways, which are usually associated with loss of function, are occasionally accompanied by dramatic evidence of hyperfunction. Scadding and Koltzenburg (2006) reported that "touch-evoked pain in neuropathic conditions is signaled on the skin by sensitive mechanoreceptors with large myelinated axons that normally encode non-painful tactile events". But no one pointed out that the first consequence of an axotomy is a hypoaesthetic territory on the skin - it is perhaps too evident - and that the painful complication of "tenderness to touch" is located on the same territory as the hypoaesthesia, which is on the partial cutaneous territory of partial denervated nerves, even if the neural mechanisms underlying SMA are presumably central. Therefore, we conclude that a SMA mapped using allodynography is, in humans with neuropathic pain, the sign of a peripheral axotomy of large myelinated $\mathrm{A} \beta$ fibres, which normally evoke nonpainful tactile sensations. This interpretation does not exclude, in addition, a possible contribution of the small, unmyelinated fibres.

The surface on the skin of the SMA territory is usually larger than the hypoaesthetic territoryextraterritorial pain - as determined by the secondary aesthesiography but, if the mechanisms of activation, modulation, or even modification producing pain hypersensitivity (Woolf and Salter 2000) are not followed through, we have a situation where the SMA territory is smaller than the hypoaesthetic territory.

The time course of disappearance from one rainbow pain scale value into the next one is not linear (Figure 7). It takes longer to overcome a green rainbow pain scale ( $1.5 \mathrm{~g}$ provoking pain) than to overcome a blue rainbow pain scale $(3.6 \mathrm{~g})$. It takes 49.9 days $\pm \mathrm{SD}=32.9$ days to overcome a green rainbow pain scale whereas it takes 33.7 days $\pm S D=20.8$ days to overcome a blue rainbow pain scale. These time intervals are values of great interest for the therapist and the patient, as they allow estimating the duration of DVCS treatment, that is, the step by step disappearance of the SMA territory.

\section{Conclusions}

The aim of this study was to investigate whether a SMA territory is modified in the course of the DVCS treatment. The absence so far in the literature of a relationship between hypoaesthesia and mechanical allodynia has been brought about by the fact that they are distinct expressions of nerve axotomy occurring at different moments. This study shows the disappearance of a SMA territory, replaced by an underlying hypoaesthesia. "The precise and high quality mapping of allodynia performed in somatosensory rehabilitation is a precious source of information for our understanding of abnormal sensory processing in neuropathic pain patients" (Decosterd 2006). Therefore, the mapping of SMA territories using allodynography diagnoses axonal lesions and their underlying hypoaesthesia. These are painful hypoaesthesia which are so difficult to cope with. This conclusion has clinical applications: according to the Complex Regional Pain Syndrome (CRPS) Diagnosis Criteria (Bruehl et al. 1999), mechanical allodynia is considered to be a sensory sign with a corresponding symptom of "hyperaesthesia" because the patient himself perceives the stimulus which does not normally provoke pain as painful. In fact, the patients, when asked about their sensation, prefer using the word "hypersensitivity" (Woolf 1983, 1994), "tenderness" (Perttunen et al. 1999), or "tender" in the McGill Pain Questionnaire (Melzack 1975) to describe this phenomenon.

\section{Acknowledgements}

The authors wish to thank Professor Isabelle Decosterd, MD; Professor Alain Golay, MD; Eric Buchser, MD; Federico Balagué, MD; and Nicholas Marcer, DO MSc Ost for critical review of an earlier version of the manuscript; Véronique Moret for figures; Dominique Antiglio, BSc (Hons) Ost; Anouchka Bender, OT; Rebekah Della Casa, OT; Murielle Rouiller, Frank Grothe, and Dr Clive Brown for editorial comments.

\section{Notes}

1. In this article in French, the PPT was for the first time adapted to test an underlying hypoaesthesia: the short-form PPT score is given by the mean value of the force application of the three aesthesiometers detected in an ADA series. In the original 
method to test an hypoaesthesia, the PPT score was given by the mean value of the force application of the six aesthesiometers detected in an ADADAD series.

2. In this chapter in French was first described this procedure to test during a session either the allodynography or the rainbow pain scale, but never both simultaneously.

\section{References}

Albrecht PJ, Hines S, Eisenberg E, Pud D, Finlay DR, Connolly MK, Davar G, Rice FL. 2006. Pathologic alterations of cutaneous innervation and vasculature in affected limb from patients with complex regional pain syndrome. Pain 120:244-266.

Bennett GJ. 1994. Neuropathic pain. In: Wall PD, Melzack R, editors. Textbook of pain, 3rd. Edinburgh: Churchill Livingstone. pp 201-224.

Bennett GJ, Xie YK. 1990. A peripheral mononeuropathy in rat that produces disorders of pain sensation like those seen in man. Pain 42:253-255.

Bruehl S, Harden RN, Galer BS, Saltz S, Bertram M, Backonja M, Gayles R, Rudin N, Bhudra MK, StantonHicks M. 1999. External validation of IASP diagnostic criteria for Complex Regional Pain Syndrome and proposed research diagnostic criteria. Pain 81:147-154.

Campa JA III, Payne R. 1993. Pain syndromes due to cancer treatment. In: Patt RB, editor. Cancer pain. Philadelphia: J. B. Lippincott. pp 41-56.

Campbell JN. 2001. Nerve lesions and the generation of pain. Muscle Nerve 24:1261-1273.

Campbell JN, Meyer RA. 2006. Mechanisms of neuropathic pain. Neuron 52:77-92.

Cervero F, Laird JMA. 1996. Mechanisms of touch-evoked pain (allodynia): A new model. Pain 68:13-23.

Decosterd I. 2006. Neuropathic pain symptoms: Toward mechanism-based pain management? [Editorial]. e-News Somatosens Rehabil [serial online] 3:2-5. Available: http://www.unifr.ch/ neuro/rouiller/somesthesie/somato.enews.php.

Decosterd I, Woolf CJ. 2000. Spared nerve injury: An animal model of persistent peripheral neuropathic pain. Pain 87:149-158.

Dellon AL. 2000. Somatosensory testing and rehabilitation Baltimore: The Institute for Peripheral Nerve Surgery.

Devor M. 1994. The pathophysiology of damaged peripheral nerves. In: Wall PD, Melzack R, editors. Textbook of pain, 3rd. Edinburgh: Churchill Livingstone. pp 79-100.

Devor M. 2006. Response of nerves to injury in relation to neuropathic pain. In: McMahon SB, Koltzenburg M, editors. Wall and Melzack's textbook of pain, 5th ed. Philadelphia: Elsevier. pp 905-927.

Fields HL. 1994. Peripheral neuropathic pain: An approach to management. In: Wall PD, Melzack R, editors. Textbook of pain, 3rd. Edinburgh: Churchill Livingstone. pp 991-996.

Fields HL, Rowbotham M, Baron R. 1998. Postherpetic neuralgia: Irritable nociceptors and deafferentation. Neurobiol Dis 5:209-227.

Frey $M$ von. 1896. Untersuchung über die Sinnesfunktion der Menschlichen Haut: Erste Abhandlung: Druckempfindung und Schmerz. Des XXIII Bandes der Abhandlungen der mathematisch-Physischen Classe der Königlichen Sächsischen Gesellschaft des Wissenschaften. Leipzig: S. Hirzel, III:175-266. [Translated in: Handwerker HO, Brune K, editors. 1987. Classical German contributions to pain research. pp. 69-131.

Galer BS, Rowbotham M, Perander J, Friedman E. 1999. Topical lidocaine patch relieves postherpetic neuralgia more effectively than a vehicle topical patch: Results of an enriched enrolment study. Pain 80:533-538.
Gracely RH, Lynch SA, Bennett GJ. 1992. Painful neuropathy: Altered central processing maintained dynamically by peripheral input. Pain 51:175-194.

Hendry SHC, Hsiao SS, Bushnell MC. 1999. Somatic sensation. In: Zigmond MJ, Bloom FE, Landis SC, Roberts JL, Squire LR, editors. Fundamental neuroscience. San Diego: Academic Press. pp 761-789.

Inbal R, Rousso M, Ashur H, Wall PD, Devor M. 1987. Collateral sprouting in skin and sensory recovery after nerve injury. Pain 28:141-154.

Inui K, Tsuji T, Kakigi R. 2006. Temporal analysis of cortical mechanisms for pain relief by tactile stimuli in humans. Cereb Cortex 16:355-365.

Ji RR, Kohno T, Moore KA, Woolf CJ. 2003. Central sensitization and LTP: Do pain and memory share similar mechanisms?. Trends Neurosci 12:696-705.

Ji RR, Woolf CJ. 2001. Neuronal plasticity and signal transduction in nociceptive neurons: Implications for the initiation and maintenance of pathological pain. Neurol Dis 8:1-10.

Kim SH, Chung JM. 1992. An experimental model for peripheral neuropathy produced by segmental spinal nerve ligation in the rat. Pain 50:355-363.

Létiévant E. 1876. Esthésiographie. In: Compte rendu de la $4^{\text {ème }}$ session de Nantes en 1875. Paris: Association française pour l'avancement des sciences. pp. 1037-1043.

Mackinnon SE. 1988. Myelinated afferents signal the hyperalgesia associated with nerve injury. Pain 32:89-94.

Malan TP, Ossipov MH, Gardell LR, Ibrahim M, Bian D, Lai J, Porreca F. 2000. Extraterritorial neuropathic pain correlates with multisegmental elevation of spinal dynorphin in nerveinjured rats. Pain 86:185-194.

Malenfant A, Forget R, Amsel R, Papillon J, Frigon JY, Choinière M. 1998. Tactile, thermal and pain sensibility in burned patients with and without chronic pain and paresthesia problems. Pain 77:241-251.

Mannion RJ, Costigan M, Decosterd I, Amaya F, Ma QP, Holstege JC, Ji RR, Acheson A, Lindsay RM, Wiolkinson GA, et al. 1999. Neurotrophins: Peripherally and centrally acting modulators of tactile stimulus-induced inflammatory pain hypersensitivity. Proc Natl Acad Sci USA 96:9385-9390.

Melzack R. 1975. The McGill Pain Questionnaire: Major properties and scoring methods. Pain 1:277-299.

Melzack R, Wall PD. 1965. Pain mechanisms: A new theory. A gate control system modulates sensory input from the skin before it evokes pain perceptions and response. Science 150:971-979.

Merskey H. 1979. Pain terms: A list with definitions and notes on usage. Pain 6:247-252.

Merskey H, Bogduk N, editors. 1994. Classification of chronic pain: Descriptions of chronic pain syndromes and definitions of pain terms. 2nd ed. Seattle: IASP Task Force on Taxonomy.

Mitchell SW. 1872. Injuries of nerves and their consequences Philadelphia: J. B. Lippincott.

Nahra H, Plaghki L. 2003. Modulation of perception and neurophysiological correlates of brief $\mathrm{CO}_{2}$ laser stimuli in humans using concurrent large fiber stimulation. Somatosens Mot Res 20:139-147.

Noël L, Spicher CJ, Degrange B, Rouiller EM. 2005. Une esthésiographie intestable signe des lésions axonales ou comment cartographier une hypoesthésie douloureuse. In: Izard $\mathrm{MH}$ Nespoulous $\mathrm{R}$, editors. Expriences en ergothrapie. 18th Tome. Montpellier, Paris: Sauramps medical. pp 127-135.

Oaklander AL, Rissmiller JG, Gelman LB, Zheng L, Chang Y, Gott R. 2006. Evidence of focal small-fiber axonal degeneration in complex regional pain syndrome-I (reflex sympathetic dystrophy). Pain 120:235-243. 
Ossipov MH, Lai J, Malan TP, Porreca F. 2000. Spinal and supraspinal mechanisms of neuropathic pain. Ann NY Acad Sci 909:12-24.

Perttunen K, Tasmuth T, Kalso E. 1999. Chronic pain after thoracic surgery: A follow-up study. Acta Anaesthesiol Scand 43:563-567.

Rowbotham MC, Davies PS, Verkempinck C, Galer BS. 1996a. Lidocaine patch: Double-blind controlled study of a new treatment method for post-herpetic neuralgia. Pain 65:39-44.

Rowbotham MC, Fields HL. 1989. Post-herpetic neuralgia: The relation of pain complaint, sensory disturbance, and skin temperature. Pain 39:129-144.

Rowbotham MC, Fields HL. 1996. The relationship of pain, allodynia and thermal sensation in post-herpetic neuralgia. Brain 119:347-354

Rowbotham MC, Yosipovitch G, Connolly MK, Finlay D, Forde G, Fields HL. 1996b. Cutaneous innervation density in the allodynic form of postherpetic neuralgia. Neurobiol Dis 3:205-214

Scadding JW, Koltzenburg M. 2006. Painful peripheral neuropathies. In: McMahon SB, Koltzenburg M, editors. Wall and Melzack's textbook of pain, 5th ed. Philadelphia: Elsevier. pp 973-999.

Semmes J, Weinstein S, Ghent L, Teuber HL. 1960. Somatosensory changes after penetrating brain wounds in man Cambridge, MA: Harvard University Press.

Sindrup SH, Andersen G, Madsen C, Smith T, Brosen K, Jensen TS. 1999. Tramadol relieves pain and allodynia in polyneuropathy: A randomised, double-blind, controlled trial. Pain 83:85-90.

Spicher C, Kohut G. 2001. Jean Joseph Emile Létiévant: A review of his contributions to surgery and rehabilitation. J Reconstr Microsurg 17:169-177.

Spicher CJ. 2006. Handbook for somatosensory rehabilitation Montpellier, Paris: Sauramps Médical, [The English translation of: Spicher C. 2003. Manuel de rééducation sensitive du corps humain. Genève, Paris: Médecine \& Hygiène].

Spicher CJ, Degrange B, Mathis F. 2005. The vibrotactile sense assessment: A path to relieve chronic neurological pain. e-News Somatosens Rehabil [serial online] 2:49-61. Available: http:// www.unifr.ch/neuro/rouiller/somesthesie/somato.enews.php

Spicher CJ, Degrange B, Mathis F. 2006. La désactivation des signes d'irradiation provoquée; Une nouvelle technique de rééducation sensitive pour traiter les douleurs chroniques. ergOThérapies 22:13-18.

Sukhotinsky I, Ben-Dor E, Raber P, Devor M. 2004. Key role of the dorsal root ganglion in neuropathic tactile hypersensibility. Eur J Pain 8:135-143.

Tinel J. 1917. Nerve wounds. London: Baillère, Tindall and Cox, [The English translation of: Tinel J. 1916. Les blessures de nerfs. Paris: Masson].

Trotter WM, Davies HM. 1907. The exact determination of areas of altered sensibility. Rev Neurol Psychiatry 5:761-772.

Woolf CJ. 1983. Evidence for a central component of post-injury pain hypersensitivity. Nature 306:686-688.

Woolf CJ. 1994. The dorsal horn: State-dependent sensory processing and the generation of pain. In: Wall PD, Melzack R, editors. Textbook of pain, 3rd ed. Edinburgh: Churchill Livingstone. pp 101-112.

Woolf CJ, Mannion RJ. 1999. Neuropathic pain: Aetiology, symptoms, mechanisms, and management. Lancet 353:19591964.

Woolf CJ, Salter MW. 2000. Neuronal plasticity: Increasing the gain in pain. Science 288:1765-1768.

Woolf CJ, Salter MW. 2006. Plasticity and pain: Role of the dorsal horn. In: McMahon SB, Koltzenburg M, editors. Wall and Melzack's textbook of pain, 5th ed. Philadelphia: Elsevier. pp 91-105.
Wu G, Ringkamp M, Hartke TV, Murinson BB, Campbell JN, Griffin JW, Meyer RA. 2001. Early onset of spontaneous activity in uninjured C-fiber nociceptors after injury to neighboring nerve fibers. J Neurosci 21:RC140:1-5.

Yen LD, Bennett GJ, Ribeiro Da Silva A. 2006. Sympathetic sprouting and changes in nociceptive sensory innervation in the glabrous skin of the rat hind paw following partial peripheral nerve injury. J Comp Neurol 495:679-690.

Ziegler EA, Magerl W, Meyer RA, Treede RD. 1999. Secondary hyperalgesia to punctuate mechanical stimuli. Central sensitization to A-fibre nociceptor input. Brain 122:2245-2257.

\section{Appendix A: Experimental protocol for allodynography}

- The stimulus is applied at multiple locations on the skin.

- The stimulus is arbitrarily fixed at an applied force of $15 \mathrm{~g}$ (pressure: $69.1 \mathrm{~g} / \mathrm{mm}^{2}$ ).

- The pain invariant is defined as $3 / 10 \mathrm{~cm}$ on a visual analogue scale (VAS) or the pain at rest $+1 \mathrm{~cm}$ (see Figure 3B).

\section{Objective: To map the SMA territory}

Material.

- A4, possibly A3 millimetric graph paper.

- $15 \mathrm{~g}$ aesthesiometer (Semmes-Weinstein: mark 5.18).

- Visual analogue scale of pain understood by the patient.

Test procedure. The limb to be examined should be stable, if necessary stabilized by the examiner's hand.

Type of stimulation. The pressure to be applied to the aesthesiometer by the therapist is the minimum force required to bend the nylon filament. At the beginning, skin stimulation is rapid and then, as the precise zone is approached, stimulation should be for $2 \mathrm{~s}$ and the interval between questions $8 \mathrm{~s}$. The interstimulus interval (ISI) is thus $10 \mathrm{~s}$, to be counted mentally.

Choice of the pain invariant. Great attention is required during the initial testing. In particular, the patient is asked, "Can you imagine a worst possible pain?" A pain for the search of the allodynic territory is fixed at $3 / 10 \mathrm{~cm}$. In this way, a large vertical red line is traced at a pain of $3 / 10$, which is marked "STOP", thus representing the pain invariant.

Explanations on the allodynography procedure are given to the patient: the aesthesiometer is pressed against the skin of a non-painful limb, and the patient is told that the place evoking moderate pain is being sought; the "STOP" mark is shown to him at the same time. He is asked to look at the scale and using his finger, to progress along the 
"no pain" line to the "STOP" mark when pain begins to appear. The patient replies by "STOP" when the stimulus provokes a pain corresponding to $3 / 10$.

Localization. On the longitudinal axis of the limb, from proximal to distal, the first allodynic point is found by moving the stimulus site centimetre by centimetre. The patient is asked if the pain is red (line colour at $3 \mathrm{~cm}$ on the visual analogue scale): if no, the test is continued moving the stimulus further; if yes, move the stimulus back from distal to proximal in order to find a less painful stimulation site. Then, move again from proximal to distal, but now advancing millimetre by millimetre in order to find the first allodynic point along this axis. Mark the final stimulated site on the paper, trace the axis that was followed, and add an arrow (see Figure 1). Carry out the procedure on the perpendicular axes. Finally, trace a polygon by joining the border sites obtained along the various axes investigated.

Result. This is the $15 \mathrm{~g}$ allodynic (SMA) territory for a pain invariant of $3 / 10 \mathrm{~cm}$ on a VAS.

\section{Appendix B: Experimental protocol for the rainbow pain scale}

- The tactile stimulus is delivered using the following seven aesthesiometers: $0.03 \mathrm{~g}$ (red); $0.2 \mathrm{~g}$ (orange); $0.7 \mathrm{~g}$ (yellow); $1.5 \mathrm{~g}$ (green); $3.6 \mathrm{~g}$ (blue); $8.7 \mathrm{~g}$ (indigo); $15 \mathrm{~g}$ (violet). They correspond to every other monofilament in the Semmes-Weinstein kit of 20.

- The visual analogue pain scale validated by the patient during allodynography is also used: the pain invariant is defined as $3 / 10 \mathrm{~cm}$ on a visual analogue scale (VAS) or the pain at rest $+1 \mathrm{~cm}$.

Objective: To determine the severity of the SMA by determining the slightest aesthesiometer, from red to violet, provoking pain

Material

- A4, possibly A3 millimetric graph paper.

- Seven aesthesiometers: $0.03 \mathrm{~g}$ (SemmesWeinstein: mark 2.44); $0.2 \mathrm{~g}$ (mark: 3.22); $0.7 \mathrm{~g}$ (mark: 3.84 ); $1.5 \mathrm{~g}$ (mark: 4.17); $3.6 \mathrm{~g}$ (mark: 4.56); $8.7 \mathrm{~g}$ (mark: 4.93); $15 \mathrm{~g}$ (mark: 5.18)

- The VAS validated by the patient during allodynography.

Test procedure. The limb to be examined should be stable, if necessary stabilized by the examiner's hand.
Type of stimulation. The pressure to be applied to the aesthesiometer by the therapist is the minimum force required to bend the nylon filament. The application of the stimulus must last $2 \mathrm{~s}$ with an interval of $8 \mathrm{~s}$ between questions. The interstimulus interval is thus $10 \mathrm{~s}$, to be counted mentally.

Choice of the pain invariant. Same as above for allodynography.

Explanations on the rainbow pain scale procedure are given to the patient: the aesthesiometer is pressed against the non-painful limb, making it clear that it is not the same one as used for allodynograhy. The patient is told that a search is being made for the place where moderate pain is provoked while, at the same time, he is shown the "STOP" mark on the VAS. Using the index finger, the patient is instructed to advance along the "no pain" line to the "STOP" mark when pain begins to appear. The patient says "Stop", when the stimulus provokes a pain of 3/10 on the VAS.

Localization. Within the allodynic territory, using the $0.03 \mathrm{~g}$ aesthesiometer along the long axis of the limb, from proximal to distal, the first painful point is determined, advancing centimetre by centimetre. The patient is asked if the pain is red. If not, the test is continued. If yes, the aesthesiometer is moved back from distal to proximal in order to find a less painful point. Then, it is moved forward along the same axis from proximal to distal, but now advancing millimetre by millimetre, in order to find the first red point on the rainbow pain scale. The site found on the paper is marked in RED, the axis that was followed traced, and an arrow added. The same procedure is performed on the perpendicular axes. Finally, a polygon is traced by joining up the registered sites. In such a case, the patient presents a red rainbow pain scale of $0.03 \mathrm{~g}$, corresponding to a pain invariant of $3 / 10 \mathrm{~cm}$ on the VAS.

In case the $0.03 \mathrm{~g}$ aesthesiometer does not provoke pain, which was fortunately the case in most patients, the whole procedure is repeated with the "orange" aesthesiometer $(0.2 \mathrm{~g})$. If the latter does not provoke pain either, the procedure is repeated with the "yellow" aesthesiometer $(0.7 \mathrm{~g})$, and so on until the first painful aesthesiometer is found. In the most favourable case for the patient, it will be the one used for the allodynography, namely, the violet aesthesiometer $(15 \mathrm{~g})$. Whenever the aesthesiometer provoking pain is found, the determination of the border points is done along the different axes to obtain the final polygon (as explained above).

Result. The patient consequently presents a rainbow pain scale of a colour corresponding to the first painful aesthesiometer, going from red to violet, using a pain invariant of $3 / 10 \mathrm{~cm}$ on the VAS. 
Appendix C: Experimental protocol for the secondary aesthesiography

Objective: To map the boundaries of the underlying hypoaesthetic territory present after disappearance of the $S M A$ territory

Material

- A4 millimetric graph paper for the hand or possibly A3 for the hand together with the forearm.

- Set of 20 Semmes-Weinstein pressure aesthesiometers.

Test procedure. The limb to be examined should be stable, if necessary stabilized by the examiner's hand. Type of stimulation. The pressure to be applied to the aesthesiometer by the therapist is the minimum force required to bend the nylon filament. The stimulation on the skin should only last for $2 \mathrm{~s}$ and the interstimulus interval should be $8 \mathrm{~s}$. The time between each monofilament application is thus $10 \mathrm{~s}$, to be counted mentally.

Choice of aesthesiometer by the therapist. In a descending series, the last aesthesiometer detected on the contralateral side is determined, for instance, it is $0.1 \mathrm{~g}$ (mark: 2.83) on the palm and $0.2 \mathrm{~g}$ (mark: 3.22) on the dorsal face of the hand. Subsequently, select two aesthesiometers next to the first aesthesiometer detected, both in the ascending and descending directions. This series of five aesthesiometers is then used for delineating the hypoaesthetic territory. If the aesthesiometer is too small, the contour will be imprecise. If on the contrary, it is too large, there will be no hypoaesthetic territory.

Explanations on the determination of the secondary aesthesiography are given to the patient: the aesthesiometers are shown to the patient, who is told that he is going to be touched by some of them in order to determine the territory where he feels less than normal. He is asked to look away by turning his head slightly to the side. The patient replies by touched as soon as he detects the stimulus.

Localization. In order to help the therapist trace the final polygon, it is easier to place the graph paper besides the hand and parallel to it, so that he only has to mentally effect a transfer between the hand and the recording paper.

Longitudinal axis. The first point not detected by the patient is identified. On the longitudinal axis, from the proximal to the distal, the first stimulating site not perceived by the patient is determined, advancing centimetre by centimetre. Move back from distal to proximal in order to find the first detected point. Finally, the first point not detected along this axis is found by moving forward again from proximal to distal, but now advancing millimetre by millimetre.

Transverse axis. Search the first point not detected by the patient along the axis perpendicular to the presumed damaged nerve. On the axis from right to left (e.g., for a palm face of a right hand, in case of lesion of the ulnar nerve), search the first point not detected by the patient, advancing centimetre by centimetre. Then return towards the right to find the first point detected. The next step is to return towards the left, but advancing millimetre by millimetre, in order to find the first point not detected on the transverse axis. Finally, mark the point found on the paper and trace with an arrow the axis that was considered. If necessary, continue the search for other points on the lines: transverse axis of the metacarpal heads, transverse axis of the PIP, longitudinal axis from distal to proximal, etc.

Result. Trace a polygon joining up the points determined, reflecting the extent and position of the underlying hypoaesthetic territory. 